\title{
O PODER FAMILIAR E A SUA PROTEÇÃO CONSTITUCIONAL
}

\author{
Rubiana Aparecida Pio da Costa, Ana Augusta R. Westin Ebaid
}

Universidade do Oeste Paulista - UNOESTE, curso de Direito, Presidente Prudente, SP. E-mail: anaaugusta@unoeste.br

\section{RESUMO}

O objetivo geral da pesquisa é estudar direito de família, em especial no que se refere à importância do Estado nas relações familiares, bem como seus limites de interferências e seu direito diante do poder familiar dos pais. Serão apresentados os princípios fundamentais no que tange à família e ao objetivo principal deste trabalho, que consiste em verificar quais as formas e os limites de intervenção do Estado no âmbito familiar. Primeiramente, será abordado o conceito da família tradicional e sua importância na sociedade. Em seguida, serão abordadas as consequências da indiferença Estatal, bem como as ideologias que tendem a destruir tal modelo familiar. Ao se fazer uma correlação de todos os temas abordados, no final ficará demonstrado que o Estado intervém, diretamente, no poder familiar, extrapolando os limites impostos por lei.

Palavras-chave: Família; Proteção do Estado; Princípios Constitucionais.

\section{POWER FAMILY AND YOUR CONSTITUTIONAL PROTECTION}

\begin{abstract}
The overall objective of the research is to study family law, particularly with regard to the importance of the state in family relationships, as well as its limits interference and its right in front of the family power of parents. The fundamental principles will be presented regarding the family and the aim of this work, which is to check what forms and limits of state intervention in the family. First, will address the concept of the traditional family and its importance in society. Then the consequences will be addressed the State indifference and ideologies that tend to destroy this family model. When making a correlation of all the topics covered in the end it will be shown that the state intervenes directly in the family power, extrapolating the limits imposed by law.
\end{abstract}

Keywords: Family; State Protection; Constitutional Principles. 


\section{INTRODUÇÃO:}

Um dos grandes problemas atuais é a perda de valores, perda do verdadeiro conceito de família, perda da autoridade familiar, perda da seguridade jurídica, perda da proteção e da real função do Estado.

Este trabalho tem por escopo efetuar uma análise reflexiva sobre a importância da família tradicional, que se encontra protegida constitucionalmente, e que é o alicerce da sociedade, já que desempenha papel fundamental no desenvolvimento do ser humano e que, mesmo assim, vem sido desvalorizada.

Objetiva ressaltar a interferência estatal abusiva nas relações familiares e a incompetência do Estado na efetivação da aplicação das leis, no cuidado com a segurança, a saúde e a educação dos cidadãos. De igual forma, objetiva apresentar algumas das inconstitucionalidades existentes no pátrio ordenamento jurídico, a desnecessidade da criação de leis que já se encontram previstas, a criação de leis que favorecem, somente, parte da sociedade e que maculam valores.

Após breve reflexão, o estudo em tela tem por objetivo demonstrar a intenção Estatal na supressão da liberdade individual e o regresso jurídico, ao permitir a violação aos direitos fundamentais previstos na Magna Constituição Federal, em especial o direito à vida e à igualdade.

\section{METODOLOGIA}

Trata-se de uma reflexão embasada em bibliografia diversa, fundamentada em leis, doutrinas, escritos e experiência pessoal. Cientificamente, é importante, pois nos remete à oportunidade de aprofundar o conhecimento e contribuir, para que a temática amplie espaço cada vez mais efetivo nas preocupações da comunidade acadêmica das ciências jurídicas.

\section{RESULTADOS}

A família é a célula originária da vida social, é ela a sociedade natural, o inicio da vida em sociedade. Denomina-se porfamília o conjunto de pessoas que possuem grau de parentesco consanguíneo ou afinidade entre si. A família é considerada uma instituição responsável, por promover a educação dos filhos e influenciar o comportamento dos mesmos no meio social. O papel da família, no desenvolvimento de cada indivíduo, é de fundamental importância. É no seio familiar que são transmitidos os valores morais e sociais que servirão de base para o processo de socialização da criança, bem como as tradições e os costumes perpetuados através de gerações. 
A família é a base, o esteio, o sustento de uma sociedade mais justa. Ao longo da história da humanidade, assistiu-se à destruição de nações grandiosas por causa da dissolução dos costumes, de valores sendo invertidos, sendo motivados pela desvalorização da família.

\section{DISCUSSÃO}

Uma família tradicional é normalmente formada por pai e mãe, unidos por matrimônio ou união de fato e por um ou mais filhos.

Ensina o professor Flávio Tartuce (2013, p.27):

A Constituição Federal de 1988 tem um capítulo próprio, que trata da família, da criança, do adolescente e do idoso (Capítulo VII, do Título VIII - Da Ordem Social). Interpretando-se um dos dispositivos constantes desse capitulo, o art. 226 do Texto Maior, pode-se dizer que a família é decorrente dos seguintes institutos:

- Casamento civil, sendo gratuita a sua celebração e tendo efeito civil o casamento religioso, nos termos da lei (art. 226, §§ 1.ㅇ e 2으);

- União estável entre homem e mulher, devendo a lei facilitar a sua conversão em casamento (art. 226, § $3^{\circ}$ ). A união estável está regulamentada nos artigos de 1.723 a 1.727 do CC, sem prejuízo de outros dispositivos da atual codificação.

Entende-se, portanto, que a única família amparada pelo pátrio ordenamento jurídico é aquela que decorre do casamento/união entre homem e mulher, e não há de se falar em outro tipo de família, como vem sido imposta atualmente.

Quanto ao tema, ensina o escritor David Francisquini (2012, p.112):

Embora a união estável e o casamento sempre ocorram entre um homem e uma mulher, não ocorrem entre qualquer homem e qualquer mulher. Não pode haver casamento, por exemplo, entre irmão e irmã, entre pai e filha ou entre genro e sogra. Esses impedimentos, baseados na consanguinidade e na afinidade (art. 1.521, CC), aplicam-se, também, à união estável (art. 1.723, § $\left.1^{\circ}, \mathrm{CC}\right)$. A diversidade de sexos é necessária, não se reconhece união estável entre homem e mulher impedidos de casar (art. 1.727).

A família pode ser entendida como a célula-mater da sociedade, ou seja, o sustentáculo da mesma. É na família que se observam as primeiras formas de organização, de autoridade, regras e submissão. É pela autoridade dos pais que os filhos passam a obedecer a regras dentro da sua família e de sua vida e logo mais, passam a sujeitar-se as normas jurídicas. Carlos Roberto Gonçalves (2012, p. 17), traz: "De modo geral, as pessoas provêm de um organismo familiar e a ele conservam-se vinculadas durante a sua existência". Cumpre, portanto, salientar-se que é na família que são implantados os costumes e os valores. 
Tomás de Aquino ao falar sobre família, questiona o porquê de existirem as leis. A resposta habitual seria "para estabelecer a ordem numa sociedade". O referido autor vai além: "as leis servem, para desenvolver as virtudes no ser humano".

Ora, as virtudes se adquirem por duas vias: uma dolorosa (as leis) e uma amorosa (na família). As leis impõem aos indivíduos penas, caso as leis não sejam cumpridas, e por isto podem ser chamada de "dolorosas". Já dentro da família, o indivíduo vai aprendendo e se conformando, cotidianamente, a viver de forma virtuosa. Isso facilita, muito, o processo, uma vez que o tutor é uma pessoa em que ele confia e tem laços afetivos (normalmente o pai com a ajuda da mãe).

É evidente, no cotidiano, a imagem deturpada de família, que vem sendo imposta à sociedade. Falar sobre família, futebol ou religião, traz constrangimentos, é causa de repulsa. Os órgãos estatais, que deveriam protegê-las, conforme a Magna Constituição Federal, vêm lutando, para criar uma imagem de família minimalista, com o principal objetivo de tomar para o Estado o poder familiar, fazer do mesmo o detentor de todo o poder.

Se a família, que é a base da sociedade, for destruída, consequentemente, a sociedade será desestabilizada, caminhando, também, rumo à sua destruição. Em meio a tal caos, maiores são as chances de uma revolução triunfar. Quanto maiores forem as intervenções e o poder familiar for alienado para o Estado, menor será a liberdade de cada individuo, havendo, assim um grande regresso na história do Direito, da justiça, do país. Os direitos fundamentais à vida, à liberdade, à igualdade, à segurança e à propriedade deixarão de ser invioláveis.

O Estado não deve intervir na base da estrutura familiar, mas dar apoio e assistência às famílias. Nestes moldes, não deve o Estado retirar a base socioeducativa da família, como bem estuda Pablo Stolze e Pamplona Filho (2012, p.31.): "Ao Estado não cabe intervir no âmbito do Direito de Família a ponto de aniquilar a sua base socioafetiva".

O planejamento familiar é de livre planejamento do casal, de acordo com o artigo 1.565 , $\S$ 2o, do Código Civil, não cabendo ao Estado influenciar na base familiar.

$\mathrm{O}$ artigo 22 do Estatuto da Criança e do Adolescente e o artigo 1.634 do Código Civil estabelecem deveres a serem cumpridos pelos pais para com seus filhos e que tais deveres não podem ser transferidos, e são irrenunciáveis, exceto no caso de adoção, onde ocorre a destituição do poder familiar.

Ressalta-se, entretanto, a necessidade de liberdade, para impor limites, a fim de que esses deveres sejam efetivamente cumpridos, o que não tem sido respeitado, tendo em vista a grande disputa existente entre a família e o Estado, no que tange ao controle sobre a conduta dos indivíduos. 
Como observa Chistiane Splicido (2012, p. 57), "Trata-se de uma questão de invasão de controle do Estado sobre a vida familiar e individual, tolhendo a legitimidade e desorganizando as raízes axiológicas da família".

Embora o Estado tenha a função de proteger seus indivíduos, não se deve admitir que ele venha a intervir no âmbito familiar sem necessidade, tendo em vista que conceder tal autorização é o mesmo que abrir mão dos direitos fundamentais constitucionalmente tutelados.

Sabe-se que todos os direitos são invioláveis, não existe direito passível de violação. Mas a Constituição Federal fez questão de frisar a inviolabilidade do direito à vida, exatamente por se tratar de direito fundamental. Importante lembrar, que a Constituição Federal é a Lei Maior do país, à qual se devem reportar todas as demais leis.

Vive-se em um mundo que avança, notoriamente, em tecnologias e inovações, mas entretanto que regride, grandemente no respeito e zelo pela vida. Isso é constatado facilmente, ao deparar-se com um judiciário com extraordinária carga de processos, um imenso número de crimes, com a falta de respeito mutuo, com a criação de leis que favorecem somente parte da sociedade e que denigrem valores.

Encontra-se um exemplo no Código Penal vigente que admite duas hipóteses de aborto legal: o aborto terapêutico, que encontra previsão legal no Art. 128, I, do CP (aborto necessário); e o aborto sentimental, que está previsto no inciso II do referido artigo (aborto no caso de gravidez resultante de estupro), vindo em desacordo com as referidas leis acima citadas.

É inaceitável o fato de ser permitido ou, juridicamente falando, não ser punível o fato de um médico tirar a vida de outrem, para evitar a morte de uma mulher. Como aceitar-se que a vida desta, a quem é concedido viver, é melhor do que a daquele que tem esse direito retirado? Como balizar qual é a mais importante, se nos dois casos se trata de vidas?

Em um país que vive em uma constante luta pela igualdade e pela liberdade, poder decidir sobre a valia de uma vida torna-se contraditório todo o pátrio ordenamento jurídico. Em consonância, discorre João Paulo II: "Reivindicar o direito ao aborto e reconhecê-lo legalmente equivale a atribuir à liberdade humana um significado perverso e iníquo: o significado de um poder absoluto sobre os outros e contra os outros. Mas isto é a morte da verdadeira liberdade".

De forma corriqueira, pode-se observar o quanto vem sendo falado sobre os princípios da dignidade humana e da proporcionalidade. Entretanto nada há de tão desproporcional e indigno quanto se admitir a prática de aborto, pelo fato de a mãe ter sido vítima de estupro, é que um crime (estupro) não pode e não deve justificar outro (aborto). 
Sob este ponto de vista, não se pode desprezar o fato de que a mãe, nesses casos, fora vítima de um crime brutal, o crime de estupro. Porém não se deve esquecer que consentir o aborto é o mesmo que admitir a brutalidade do primeiro crime. E pior, dessa vez contra um ser indefeso, que tem o direito à vida, constitucionalmente assegurado (o nascituro) e que não teria qualquer possibilidade de defesa, (não teria, sequer, a chance de esboçar uma legítima defesa diante de uma agressão injusta contra sua vida). Seria o mesmo que retribuir o mal com o mal.

É evidente que o Estado não pode obrigar uma mãe a criar um filho que ela não queira, porém não só pode, como deve, usar de seus muitos mecanismos, para garantir o nascimento da vida desse ser indefeso e, ainda, assegurar-Ihe uma vida digna, quer seja com sua mãe biológica ou com uma substituta, esta última, por meio do instituto jurídico da adoção, previsto na lei 8.069/90 e no Código Civil de 2002.

Muitos dos defensores da corrente do aborto de anencéfalo se centram na argumentação dos traumas ocasionados aos pais que só ficarão com seus filhos por algumas horas ou dias, já que, supostamente, a sua morte, devido à deficiência, é certa.

De acordo com estas ideias, a respeitável ministra menciona:

Min. Cármen Lúcia: "O feto anencéfalo não tem viabilidade de desenvolver uma vida extrauterina. A anencefalia é um trauma para todos, não só para a gestante" (Votou pela procedência).

Conforme se verifica, toda a argumentação se repercute nos traumas da família, em especial da mãe, da inviabilidade de desenvolvimento da vida, da dignidade humana etc... No entanto como se podemos afirmar que uma vida não vai desenvolver-se socialmente?

Para formular esta resposta, vou relatar a minha história: Eu Rubiana Aparecida Pio da Costa, sou portadora de uma rara deficiência congênita denominada extrofia vesical. Nada foi constatado nas três ultrassonografias realizadas durante a minha gestação.

Ao nascer, vinte e um anos atrás, grande foi o susto de minha família, bem como o trauma de minha mãe. Ora, uma mulher sem quase nenhuma experiência por sua pouca idade, afinal ela só tinha vinte anos, de uma classe social baixa, ter em seus braços, uma criança com toda a barriga aberta, onde era possível verem-se até os seus órgãos internos, cheia de dores e, ao mesmo tempo, tão indefesa. Não foi nada fácil.

Os médicos da região de Presidente Prudente, onde nasci, sequer quiseram colocar as mãos em mim, pois alegavam que eu não sobreviveria ao menos uma semana. Eles, como a citada ministra, acreditavam que não havia interesse em tutelar ou lutar por uma vida que, em tese, não 
se desenvolveria socialmente, afinal, para eles, não havia viabilidade no desenvolvimento de minha vida. Este não foi o laudo de apenas um médico, mas de muitos.

Mesmo com todo o psicológico abalado, minha mãe, juntamente com minha avó, não desistiram da minha vida. Os familiares e amigos se comoveram com meu caso, entre eles um conhecido que indicou que me levassem para um hospital na cidade de São Paulo. Entretanto, se eu não morasse na referida cidade, o hospital no qual faço tratamento até hoje, não prestaria assistência. Foi, então, que esse conhecido lhes passou seu endereço e disse que com ele minha mãe e avó residíamos. Foi, então, que conseguiram as primeiras respostas para o caso da minha deficiência. Ora, onde estava o Estado e seu interesse na saúde de seus cidadãos? Se o sistema não fosse "burlado", eu teria sobrevivido?

Ao ser avaliada pela equipe medica desse hospital, passei por uma serie de exames, até que descobriram o enquadramento do meu caso. Entretanto disseram que não poderiam admitirme por falta de vagas e, ainda, que a chances de sobrevivência eram muito pequenas, devido à própria deficiência e a fortes hemorragias. Foi quando minha mãe e minha avó recorreram a muitos outros hospitais, os quais nem sequer me chamaram para uma consulta.

Ao completar quatro meses de vida, o hospital ao qual me havia avaliado me chamou para admissão no mesmo. Lá passei por um grande trajeto, sendo submetida a dezessete cirurgias. Os médicos, muitas vezes, ao se deparar com insucessos em meu caso, novamente desacreditavam em minha vida e tornavam a repetir que eu não iria sobreviver; ou, ainda, que eu não poderia desenvolver-me socialmente, que eu não poderia andar, que eu não poderia ter filhos, que eu teria que usar fraudas, enquanto vivesse, entre muitas outras coisas.

Minha mãe e minha avó, por terem pouca renda, passavam muitos dias sem comer, dormiam em cadeiras, no hospital, passavam por diversas humilhações. Pergunto: onde estava o suporte estatal quanto à saúde? Onde estava o amparo do Estado aos traumas psicológicos de minha mãe? Onde estava o direito à dignidade humana?

Hoje, apesar de tantos não acreditarem na minha sobrevivência, estou, cheia de vida, graças a Deus e às pessoas que lutaram por mim. Porem quantos são os indefesos que não têm a mesma sorte de ser presenteados com uma família como a minha?

Ressalto, portanto, a importância de se defender a vida e, ao mesmo tempo, a incompetência do Estado na efetivação dessa defesa. A vida humana não é um produto industrial, que, ao nos deparar com defeitos os descartamos. A vida é o bem mais supremo e deve ser tratada como tal. 


\section{CONSIDERAÇÕES FINAIS}

Conforme analisado ao longo deste trabalho, que objetivou um breve estudo acerca do núcleo familiar, tento relevância maior sobre a família tradicional, o poder de família e a intervenção do Estado no mesmo, com foco nos princípios da liberdade, da igualdade e da dignidade humana, tema que, conforme se teve a oportunidade de notar, é de real importância, por ser a família a base de um Estado digno.

Ficou constatado que a família é a base da sociedade, e principalmente a base do desenvolvimento do ser humano.

Verificou-se que, atualmente o poder familiar é um direito-dever, que os pais assumem para com os filhos, a fim de que a família esteja ajustada, buscando a convivência pacífica entre os seus membros, onde a sociedade prevê a igualdade entre as pessoas e isto se estende à autoridade dos pais. São poderes conferidos a estes, sempre com a finalidade de protegerem a criança ou o adolescente quanto aos perigos que possam vir a existir, bem como para a preparação da vida.

Tal poder tem sido desamparado e muitas vezes alienado do Estado. Estado que se vem se apossando de todo poder por meio de leis que visam ao interesse de uma minoria, ou, ainda, de leis que ferem os direitos fundamentais. E mais, leis que, como demonstrado, são de caráter inconstitucional, como é o caso das leis, que preveem a possibilidade de união homoafetiva, lei das palmadas pedagógicas e das leis que permitem o aborto. Sendo assim, é de fácil reconhecimento a perda da segurança jurídica.

Constatou-se, também, a falta de eficiência do Estado no cumprimento de suas principais funções, sendo: a proteção à vida, a garantia de uma boa educação, a segurança e a saúde de seus membros.

\section{REFERÊNCIAS}

AQUINO,T. SumaTeológica. Disponível em: <http://permanencia.org.br/drupal/node/1751>. Acesso em: 10 mai 2015. Disponível em: <http://issuu.com/grupogen/docs/direito_civil-vol.5tartuce/28>. Acesso em: 23 mar 2015.

FRANCISQUINI, D. Homem e Mulher Deus os Criou. 2aed. São Paulo: Artpress, 2012.

GAGLIANO, P. Novo Curso de Direito Civil, Parte Geral. 5a ed. São Paulo: Saraiva, 2004.

GONÇALVES, C. Direito Civil Brasileiro, Direito de Família. 8 ạed. São Paulo: Saraiva, 2012.

JOÃO PAULO II. Aborto: Evangelium Vitae no 20. Disponivel em: <http://aborto.aaldeia.net/joaopaulo-ii-aborto>. Acesso em: 13 abr 2015. 
MAGALHÃES, L. 0 principio da dignidade da pessoa humana e o direito a vida. 1a ed. São Paulo: Saraiva, 2012.

TARTUCE, F. Direito Civil Direito de Família. 8ae ed. São Paulo: Método,2013. 